on comparison with the table of angles given in Miller's "Mineralogy," rendered the identification of the more conspicuous planes easy. The remainıng planes were then easily determined from the relation which connects three planes lying in a zone. The forms present are : $o\left\{I_{I}\right\}$, $\left.a\left\{\mathrm{IO}^{\mathrm{I}}\right\}, r_{\{}^{\prime} \mathrm{100}\right\}, r_{1}\left\{22 \overrightarrow{\mathbf{I}}_{j}, x\{2 \mathrm{IO}\}, i\{32 \mathrm{I}\}, u \pi\{4 \overline{\mathrm{I} O}\}, u_{1} \pi\{2 \overline{2} 3\}\right.$.

I had no intention of describing the specimen at the time it was shown me, and did not pay enough attention to the physical characters of the faces to be able to recall them. The specimen was for the most part remarkably limpid, with a pale mauve tint in its purest portions. It was in part penetrated by fine delicate needles of epidote,

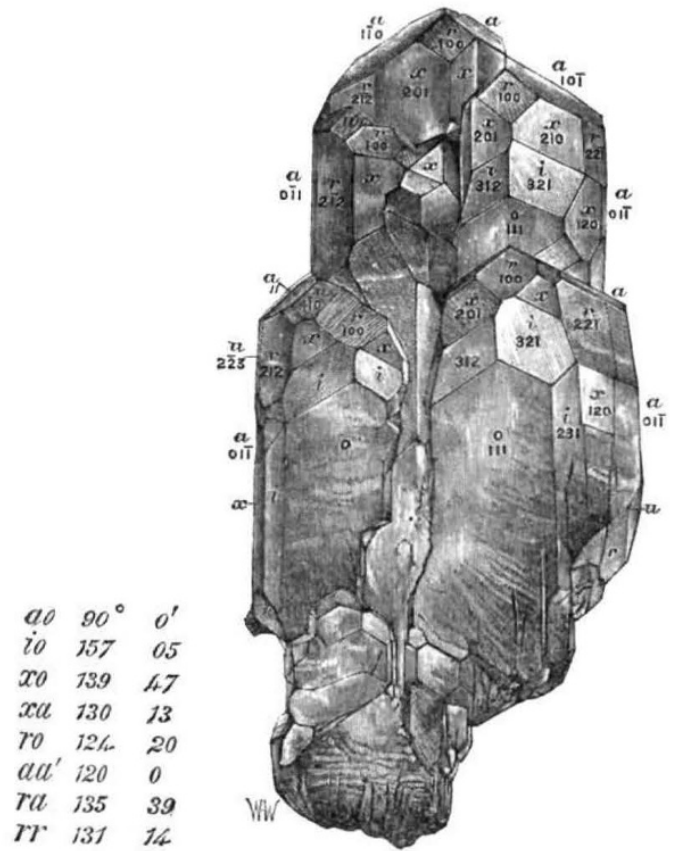

as is shown in the very excellent diagram attached, which gives a very clear and accurate idea of the specimen. A remarkably large crystal from the same locality has recently been added to the mineral collection of the Natural History Museum, Cromwell Road. It is of a much deeper mauve colour than Mr. Henson's specimen; it shows the same general forms, the planes $o$ and $\alpha$ are bright and even, but the small planes, $r, x$, $i$ are somewhat rough. These same characters are also those observed on the faces of such smaller specimens as I bave examined.

W. J. L.

\section{THE EVOLUTION OF THE AMERICAN} TROTTING-HORSE. ${ }^{1}$

THE American trotting-horse is an example of a new 1 breed of animals in process of formation. As yet it can hardly be called a definite breed in which the special and distinctive character is either fully developed in quality or satisfactorily fixed by heredity. Great progress has, however, been made, many individual animals have attained great speed, and all the better ones have derived their trotting excellence in part, at least, through heredity.

The origin of most breeds is involved in considerable obscurity, as to how much they are due to conscious and how much to unconscious selection, what motives led to this selection, how far the enhancement of the special qualities have been due to physical environment, and how far to education, training, nourishment, or cultivation.

${ }^{I}$ By Wm. H. Brewer, from the American Fournal of Science.
The formation of this new breed is so recent, the development of a special quality has been so marked, there is such an abundant literature pertaining to its history, the system of sporting "records" is so carefully planned and comprehensively conducted, and withal has become so extensive, that we have the data for a reasonably accurate determination of the influences at work which led to this new breed being made, the materials of which it is mate, and the rate of progress of the special evolution.

It is as an implement of gambling and sport that the trotter has his chief value to the biological student. Sporting events are published or recorded as the mere everyday use of animals is not, and the records of races give numerical data by which to measure the rate of progress. Similar data do not exist for the study of the evolution of any other breed.

Incidental to the preparation of a paper pertaining to this matter for farmers and breeders, I have compiled and collated certain data which have a scientific as well as economic value, the more interesting portion of which I condense for this paper.

The horse has several gaits which he uses naturally, that is, instinctively. And besides those which are natural, he has been taught several artificial ones, some of which have been much used, particularly in the middle ages. But to trot fast was not natural to horses; when urged to speed they never assumed it, and until within a century the gait was neither cultivated nor wanted by any class of horsemen. A breed of fast trotters, had it been miraculously created, would doubtless soon have perished in that it would have had no use, satisfied no fancy, and found no place in either the social or industrial world as it then was.

Before the present century the chief and almost sole uses of the horse were as an implement of war, an instrument of sport and ceremony, an index of rank and wealth, and an article of luxury.

For all these uses, as then pursued, a fast trotter was not suited, nor was he better adapted to the heavy coaches over rough roads, or the slow waggon-trains of armies. The horse best adapted to all these, however much he may have varied as to size, strength, and fleetness, was one whose fast gait was the gallop or run rather than the trot. For leisurely horseback travelling the ambling gait (or pacing gait as it came to be called in America) was preferred. With increasing use of horses for draft, certain heavy but slow breeds were developed in the Old World, of which the Dutch, Clydesdale, and Norman breeds are examples.

The causes which led to the cultivation of the trotting gait in this country, and the evolution of a breed with which it should be instinctively the fast gait, were various, and the separate value of each as a factor in the problem would be very differently estimated by different persons studying the subject from different points of view. Now that he is so valuable and plays such a part as a horse of use, it is easy to see why a breed of trotting roadsters should be produced to meet certain important demands of our modern civilisation. But this does not explain how the process actually began.

Reasoning a priori, the trotter, as a horse of use, should have originated in western Europe; as a matter of fact, he not only did not begin there, but he was unpopular there until well developed here. Locomotives began to draw armies to the battle-field, the war-horse declined in actual as well as relative importance, the modern, light, steel-spring, one-horse, convenient business waggon as well as the modern buggy came into common use after trotting as a sport was established, and after the gait had been extensively cultivated and bred to. The trottinghorse is specially adapted to various modern uses, but these uses followed his development, rather than led it, although in later days this factor has been an important one in the rate of progress. 
The influences which originally led to the starting of the breed were more social than economical ; a similar fact a century earlier marked the founding of that famous running breed, the English thoroughbred. The origin of the trotter, however, was not so simple as that, and several diverse social factors were involved, only the chief of which will here be noticed.

From early colonial times horses have been moregenerally owned by the masses of the people here than in any country of western Europe. They have had a more general use in agriculture and in business, their ownership or possession has had less social significance, and they have had less importance as instruments of gambling. The colonists who settled north of Delaware Bay, although of various nationalities, were largely those whose religious prejudices and social education was opposed to horse-racing. With the great majority of them it was considered a sort of aristocratic sport, and at best led to unthrifty ways, even if not open to the objection of positive immorality. Consequently but few race-horses were imported into this region in colonial times. The original horse stock of the northern colonies came from several European sources. England, Holland, France, and Spain certainly, and Sweden, Denmark, Germany, Ireland, and Italy probably, contributed to it. The blood from this variety of sources, variously mingled, formed the mongrel stock of the country. This was further modified by local conditions and local breeding assuming different characters in different places, and the hardships of horse life incident to a new country, with strange forage and a rough climate, caused deterioration in size and form. Early writers are unanimous on this point, but many add that what was lost in size and beauty was gained in hardiness and other useful qualities.

After the war of independence there was an improvement in the live stock of the country. English thoroughbred horses were imported both for sporting and to improve the horse stock of the country, and horse-racing rapidly grew in favour as wealth and leisure increased. The export trade in horses to the West Indies increased, particularly from New England. Pacers were most sought for this trade, but sometimes trotters were advertised for.

As horse-racing increased in the last years of the last century the opposition to it revived, and in the earlier years of the present century this became ascendant, and stringent laws forbidding the sport were passed in most of the northern States. The prohibition was sweeping and the penalties severe.

Horse-racing was then a contest between runninghorses, and during this repression of racing, trotting as a sport began, at first in a very unostentatious, irregular, and innocent sort of way. Probably no people or class of people have ever bred good horses which they prized and were proud of, who did not find pleasure in seeing them compete in speed or show their fleetness in some way, and during the repression of racing (which meant running), trotting came in as a substitute, poor though it was at first. It had a sort of encouragement from very many thrifty people who were not sportsmen, and was in a measure considered a sort of democratic sport in which even ploughhorses could take part. Racing of any kind in those days was a strife between two or more things, as it still is in most countries; no one thought that a single horse could run a race alone, but the instinctive inclination to see a spirited horse in action could be mildly gratified by letting him trot, even if single and alone, and testing by the watch how quickly a given distance could be covered. So "timing" animals came to be practised. We hear of it on the Harlem racecourse in 1806 , four years after the laws forbidding horse-racing had been enacted, and again, a little later, near Boston, and it was reputed that certain horses could trot a mile in three minutes. This speed seemed so extraordinary that in
I 818 a bet of a thousand dollars was staked (and lost) that no horse could be found that could trot a mile in three minutes. Some authorities date the beginning of trotting as a sport with this event. It is said that in the betting the odds against the successful performance of the feat were great, which shows, strikingly, the enormous progress since made in developing speed at this gait.

In 1821 , certain persons on Long Island were allowed by special statute to train, trot, etc., horses on a certain track, under certain restrictions, exempt from the penalties against horse-racing. Other organisations followed, and by I 830 the "training" of trotters was going on at several points, and trotting may be said to have become established as a sport. During this decade the record had been successively lowered to $2.40,2.34$, and 2.32 . The times of performance were carefully taken at these "trials of speed," as the statute called them, and "records" became established by more formal sporting codes.

The ostensible object of these associations was the "improvement of the breed of roadsters;" driving single horses to waggons became fashionable, and this led to the improvement of light one-horse waggons for business and pleasure. Those with steel springs were rare luxuries in 1830 ; by $r 843$, when the record of mile heats dropped to below 2.30, they were already common. During this thirteen years, the record had been lowered only half a second on mile heats, but tbree-minute horses were no longer rare.

The fashion of wealthy men driving a single fast trotter for pleasure was for a long time a peculiarly American one, and played an important part in the development of this breed. But, as stated earlier, many influences have contributed: changes in the modes of travel, changes in the methods of war, sentiments regarding horse-racing, the incentives of the course, the general improvement of roads, improvement in carriages, the needs of modern business requiring quick roadsters, these and other influences have all been at work. ${ }^{1}$

The material out of which this new breed is made is a liberal infusion of English thoroughbred blood (usually more than two generations removed), with the mongrel country stock, previously described. There is a voluminous literature relating to special pedigrees, and much speculation as to the comparative merits of the several ingredients of this composite blood.

Regarding the ideal trotter there is as yet a difference of opinion as to what the form should be, and it is too early to decide from actual results. That the gait is now hereditary, that it is the instinctive fast gait with some animals is certain, but whether this is due to inherited habit, inherited training, or to mere adventitious variation and selection, I will not discuss.

The gain in speed is given in the following table, which is the best records at mile heats, omitting the names of the special performers:

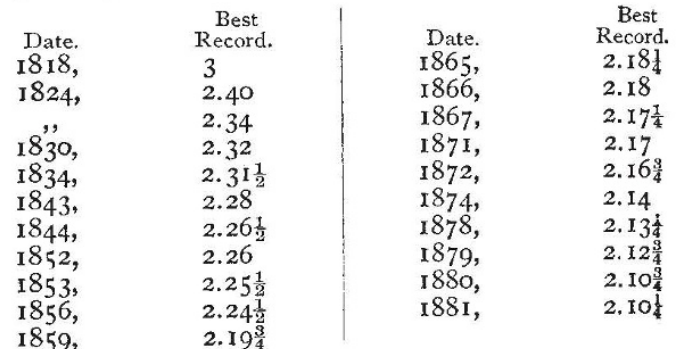

A sporting paper published in 1873 a list of three hundred and twenty-three horses, with their best records, down to the close of the preceding year. This first list

$x$ For more details regarding the history of this development and the factors involved, see the paper already cited, Rep. Conn. Bd. Agr. for I882, p. 215 . 
of the kind known to me was very imperfect in its details; it was revised for the next year, and since that time many lists, in one form or another, have been published. The figures for the animals with records of 2.25 , or better, are reasonably accurate; for the others there is much discrepancy. In the following table the numbers are my own, counting down to 1872 , inclusive ; the numbers after that date are derived from various lists published since that time in the sporing and breeding periodicals. From the very nature of t e case, the table cannot be accurate in the larger numbers, but the numbers do not lose their value for comparison with each other from such faults as to the details of the larger numbers, and, as such, it is undoubtedly the most significant series of numbers ever compiled to show progress in evolution, whether of a breed or species. The number of horses with records of 2.40 , or better, is now stated to be over five thou sand.

I leave it to mathematicians to plot the curves which immediately suggest themselves, and determine how fast horse's will ultimately trot, and when this maximum will be reached.

Table showing the numbers of Horses under the respective Records.

\begin{tabular}{|c|c|c|c|c|c|c|c|c|c|c|}
\hline & 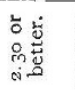 & 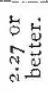 & 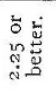 & 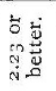 & 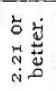 & 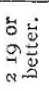 & 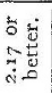 & 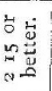 & 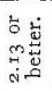 & 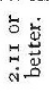 \\
\hline 1843 & I & & & & & & & & & \\
\hline I 844 & 2 & I & & & & & & & & \\
\hline I 849 & 7 & 2 & & & & & & & & \\
\hline 1852 & 10 & 3 & & & & & & & & \\
\hline 1853 & $x_{4}$ & 5 & & & & & & & & \\
\hline 1854 & 16 & 6 & & & & & & & & \\
\hline 1855 & 19 & 6 & & & & & & & & \\
\hline 1856 & 24 & 7 & I & & & & & & & \\
\hline 1857 & 26 & 7 & 2 & & & & & & & \\
\hline I858 & 30 & 7 & 2 & & & & & & & \\
\hline I859 & $3^{2}$ & 9 & 2 & I & I & & & & & \\
\hline 1860 & 40 & I I & 4 & 2 & $I$ & & & & & \\
\hline I86I & $4^{8}$ & 14 & 4 & 2 & I & & & & & \\
\hline 1862 & 54 & 17 & 7 & 4 & I & & & & & \\
\hline 1863 & 59 & 19 & 9 & 4 & I & & & & & \\
\hline I 864 & 66 & 22 & 12 & 4 & I & & & & & \\
\hline I 865 & 84 & 29 & 15 & 5 & 2 & I & & & & \\
\hline I866 & IOI & $3^{2}$ & I 7 & 6 & 3 & I & & & & \\
\hline I 867 & 124 & 42 & 21 & 9 & 5 & 2 & & & & \\
\hline I 868 & 146 & 52 & 28 & I3 & 6 & 2 & & & & \\
\hline 1869 & I7I & 63 & 34 & 15 & 10 & 4 & & & & \\
\hline 1870 & I94 & 72 & 35 & 16 & I I & 5 & & & & \\
\hline 1871 & 233 & 99 & 40 & 17 & I 2 & 6 & I & & & \\
\hline I 872 & 323 & - & - & - & - & - & - & & & \\
\hline 1873 & 376 & - & 74 & 28 & 15 & 5 & 2 & & & \\
\hline 1874 & 505 & - & 98 & 40 & 16 & I I & 5 & I & & \\
\hline 1875 & - & - & I 34 & $6 I$ & 30 & I 3 & 5 & 2 & & \\
\hline 1876 & 794 & - & 165 & $8 \mathrm{I}$ & 39 & 16 & 6 & 2 & & \\
\hline 1877 & 836 & - & 214 & 105 & 51 & 19 & 8 & 2 & & \\
\hline 1878 & $\mathrm{I}, 025$ & - & 270 & 129 & 68 & 24 & 9 & 4 & & \\
\hline 1879 & 1,142 & - & 325 & 164 & 88 & 33 & I I & 5 & I & \\
\hline 1880 & 1,210 & - & 366 & 192 & 106 & $4 \mathrm{I}$ & I 4 & 6 & 2 & I \\
\hline I 88 I & 1,532 & - & 419 & 227 & 126 & 49 & I5 & 7 & 2 & I \\
\hline 1882 & I, 684 & - & 495 & 275 & 156 & 60 & 18 & 8 & 2 & I \\
\hline
\end{tabular}

INSTITUTION OF MECHANICAL ENGINEERS

THIS Institution held their usual Spring meeting at the Institution of Civil Engineers, 25, Great George Street, on April II and I2, the president, Mr. Percy G. B. Westmacott, in the chair. Three papers were read, and discussed at length; a fourth, by Mr. A. C. Bagot, on "The Application of Electricity to Coal Mines," was postponed for want of time.

The nrst paper was by Prof. A. G. Greenhill, of Woolwich Arsenal, and dealt with the strength of shafting when exposed both to torsion and end-thrust. $\mathrm{He}$ has worked out for this case, by a complete mathematical investigation to be published in the Proceedings, the following formula :-

$$
\frac{\pi^{2}}{l^{2}}=\frac{l^{D}}{E I}+\frac{T^{2}}{4 E^{2} I^{2}}
$$

where $P=$ end-thrust, $T=$ twisting moment, $r=$ moment of inertia of cross-section, $E=$ modulus of elasticity, $l=$ maximum distance between bearings, which will allow a shaft to be stable.

When there is no twisting moment, as in a long column, the second part of the right-hand expression vanishes, and we have the ordinary formula of Euler. If there be no end-thrust, as in ordinary mill shafting, the first part vanishes. The special case where both occur together is that of the screw-shaft of a steamer; but here, it appears, on working the figures out with ordinary dimensions, that the second part is small in comparison with the first, and may be neglected. Hence a screw-shaft may so far be treated as if it were a long column only; and it follows at once that the numerous bearings interpo-ed between the engines and propeller (say, about every 25 feet) are quite unnecessary so far as stiffness is concerned. If retained, as seems desirable, simply to support the weight of the shaft, they might at least be made in some way elastic, so as to enable the shaft to accommodate itself to the sagging and straining of the vessel. It was, in fact, admitted on all hands that screw-shafts never give way from twist or thrust, but always by cross-breaking through strains induced by the unequal movements of the ship; and if so, there seems every reason for taking some steps at least in the direction which Prof. Greenhill indicates.

Another point which the paper touched upon was the question of hollow versus solid shafts. Now that shafts can be conveniently cast out of ingot steel, they are frequently made hollow, with the obvious advantage of increasing the stiffness as compared with the weight. Thus, in the case of the screw-shaft of the City of Rome, which is 25 inches diameter, with an internal hole of 14 inches diameter, it appears that the moment of inertia is 0.9 of that of an equal solid shaft, while the weight of the latter would be I 45 that of the former. Again, if a solid shaft were used of the same weight as the hollow shaft, or $20^{\circ} 7$ inches diameter, its moment of inertia, and therefore its stiffness, would be barely half that of the latter. Even if a transverse crack, I inch deep, were to occur in the hollow shaft (which it might be urged would place it at a serious disadvantage) the loss of stiffness comes out to be 6 per cent., whereas in a solid shaft of equal diameter the corresponding loss would be 5 per cent.; so that even here the advantage on the side of solidity is only I per cent.

These figures might seem to be conclusive, yet the solid shaft has its defenders. Mr. Edward Reynolds, of Messrs. Vickers and Co., stated roundly that the history of hollow screw-shafts was a mere history of disaster (whicb, however, was denied by a subsequent speaker); and he quoted some experiments of his own on shafts one-fourth the size of that in the City of Rome, where, tested under a $x$-ton weight falling from about 20 feet, the hollow shaft was rapidly destroyed, while the solid shaft remained uninjured. This occurred even when great care was taken to prevent the hollow shaft from getting flattened during the process. His explanation was that the comparatively unstrained fibres towards the centre of the section came in to support and relieve the exterior parts, whenever, by cracks or otherwise, these became unduly loaded. Prof. Kennedy, who followed, seemed to lean to the same view, and quoted the increase of stren th observable in the metal between the holes of a drilled plate, as being due, in some unexplained manner, to the influence of the unstrained metal behind the holes. A very satisfactory explanation of this fact was, however, given by Mr. Wrightson at the last meeting of the British 